\title{
BMJ Open Caregiver's readiness for change as a predictor of outcome and attendance in an intervention programme for children and adolescents with obesity: a secondary data analysis
}

\author{
Yvonne C Anderson, ${ }^{1,2}$ Gerard M S Dolan, ${ }^{3}$ Lisa E Wynter, ${ }^{1}$ Katharine F Treves, ${ }^{1}$ \\ Trecia A Wouldes, ${ }^{4}$ Cameron C Grant, ${ }^{5}$ Tami L Cave, ${ }^{2}$ Anna J Smiley, ${ }^{2}$ \\ José G B Derraik, ${ }^{2}$ Wayne S Cutfield, ${ }^{2}$ Paul L Hofman ${ }^{2}$
}

To cite: Anderson YC, Dolan GMS, Wynter LE, et al. Caregiver's readiness for change as a predictor of outcome and attendance in an intervention programme for children and adolescents with obesity: a secondary data analysis. BMJ Open 2019;9:e023195. doi:10.1136/ bmjopen-2018-023195

- Prepublication history and additional material for this paper are available online. To view these files, please visit the journal online (http://dx.doi. org/10.1136/bmjopen-2018023195).

Received 26 March 2018 Revised 4 October 2018 Accepted 9 January 2019

Check for updates

(c) Author(s) (or their employer(s)) 2019. Re-use permitted under CC BY-NC. No commercial re-use. See rights and permissions. Published by BMJ.

For numbered affiliations see end of article.

Correspondence to Dr Yvonne C Anderson; yvonne.anderson@tdhb.org.nz

\section{ABSTRACT}

Objective/design It remains unclear as to the efficacy of readiness for change measurements in child and adolescent obesity intervention programmes. This observational study aimed to determine whether the caregiver's stage of change could predict outcome and adherence to treatment in an intensive intervention programme for children and adolescents with obesity. Setting Participants were from the Whānau Pakari randomised clinical trial, a community based multidisciplinary intervention programme for obesity in Taranaki, New Zealand.

Participants Eligible participants (recruited January 2012 to August 2014) were aged 5-16 years and had a body mass index $(\mathrm{BMI}) \geq 98$ th centile or $\mathrm{BMI}>91$ st centile with weight-related comorbidities.

Interventions This study only assessed participants randomised to the high-intensity intervention programme (6-month assessments with weekly group sessions for 12 months) given attendance data were required $(n=96)$.

Primary and secondary outcome measures Primary trial outcome was BMI SD score (SDS). Secondary outcome measures included indices such as fruit and vegetable intake, 550-m run/walk time and quality of life scores. At baseline assessment, participants (if $>11$ years old) and their accompanying adult were assessed for readiness to make healthy lifestyle change.

Results A quantitative measure of stage of change in caregivers was not a predictor of primary or secondary outcomes (change in BMI SDS pre-contemplation/ contemplation $-0.08,95 \% \mathrm{Cl}-0.18$ to 0.03 , action -0.16 , $95 \% \mathrm{Cl}-0.27$ to $-0.05, \mathrm{p}=0.27$ ), or overall attendance in the weekly activity sessions $(40.0 \%$ vs $37.1 \%$, respectively, $p=0.54$ ) in the child or adolescent. Conclusions Caregiver's stage of change was not a predictor of success in this multi-disciplinary assessment and intervention programme for children and adolescents with obesity. Future research needs to determine participants' factors for success.

Trial registration number ANZCTR12611000862943; Post-results.
Strengths and limitations of this study

- This study utilised both qualitative and quantitative assessments to assess readiness for change.

- This study utilised analysis of readiness for change as a dichotomous and continuous variable.

- Limitations included the utilisation of an assessment tool that has not been used previously and a sample size that was relatively small and potentially underpowered to detect significant differences in certain outcomes.

- Preparation and action groups were merged as both were offered intervention in clinical practice. However, it could be argued that these stages of change should not be merged and therefore is a noted limitation.

\section{INTRODUCTION}

Determining whether a participant is psychologically at a point of 'readiness' to make lifestyle change is part of any consultation in clinical practice regarding changes in health. However, this is an ill-defined process and usually qualitative in nature. Readiness for change is a concept derived from the transtheoretical model defining stages of behavioural change related to addiction. ${ }^{1}$ When committing to behavioural change, an individual may transition through defined stages at variable rates and the progression is not always a linear process. Pre-contemplation is the stage where an individual can be described as feeling they 'do not have a problem'. Contemplation is when the individual acknowledges they 'may have a problem'. Preparation - the individual acknowledges they 'may have a problem and need to do something'. Action-'I will try these changes'. Maintenance — 'The changes I have made are now part of what I do'. ${ }^{1}$ 
Assessment of an individual's motivation for smoking cessation is an example of utilisation of the transtheoretical model. ${ }^{2}$ Various tools based on the original readiness for change questionnaire (based on high alcohol use) have been utilised in the obesity setting. ${ }^{3-5}$ However, little has been reported about the efficacy of readiness for change assessment in relation to outcome in children/ adolescents with obesity, and whether an individual's readiness in the 'moment in time' around an assessment will result in persistent motivation to make lifestyle change. It is too simplistic to treat all individuals the same in terms of moving through stages of change, and tailoring interventions to the individual stage of change rather than treating all participants as if they are in preparation or action stages is considered important. ${ }^{4}$ A Brazilian study of children and adolescents aged 10-18 years found that there was an association between baseline stage of change and anthropometric outcomes after a short (16week) intervention for weight (maintenance stage of change being favourable). ${ }^{6}$ Nonetheless, there was no association between adolescents' adherence to treatment and their baseline stage of change. Past international clinical practice guidelines and reviews have recommended the importance of healthcare professionals assessing readiness and barriers to change prior to implementing any healthy lifestyle plan for weight management. ${ }^{7-9}$

A parent's readiness has been identified as a key consideration in a child or adolescent's ability to make and maintain lifestyle changes. Factors associated with being at a greater degree of readiness for change in one study were having a child that was overweight, or an older child ( $\geq 8$ years), believing their own weight or their child's weight was above average, and perceiving that their child's weight was a health problem. ${ }^{5}$ Parental confidence in their ability to do well in a treatment programme was cited as the strongest predictor of treatment completion and early treatment response in an Iceland study of an 18 week intervention for 7.5-13.6year old children. ${ }^{10}$ Importantly however, this variable was not associated with child outcome at 1-year follow-up. Parental perception of their child's weight status is also an important consideration; parents' ability to identify when their child was overweight has been found to be limited. ${ }^{11}$ Parental recognition of child overweight has been found to be a predictor of behavioural intentions, but these intentions are not always translated into behaviours. ${ }^{12}$ Therefore, high parental readiness does not necessarily equate to being ready to engage in lifestyle interventions for their child affected by overweight/obesity. ${ }^{13}$

A recent systematic review of barriers and facilitators to initial (and continued) attendance in childhood weight management programmes for primary schoolaged children found that parents provide the motivation for programme commencement, largely catalysed by their worry surrounding the psychological health and well-being of their child. ${ }^{14}$ Non-modifiable predictors of initial and continued attendance included gender (programmes favoured females), ethnicity (favoured ethnic majority), family structure (favoured two-parent families) and socio-economic background (favoured lower level of deprivation). ${ }^{14}$ Body mass index (BMI) or age at entry were not associated with attendance. In the context of Aotearoa/New Zealand (NZ), engagement for Pacific Island parents/caregivers in a weight-management programme was attractive when it was family-based - providing support for each other, highlighting the importance of recognising cultural appropriateness in programmes. ${ }^{15}$ Moreover, parents can be in differing stages of change for varying aspects of healthy lifestyle change; one study demonstrated different parental stages of change for modification of their children's dietary versus physical activity behaviours. ${ }^{16}$

Clinician assessment of stage of change is usually qualitative. However, if a quantitative tool at assessment could determine the likelihood of healthy lifestyle change, this could inform prioritisation of health resources where they are more likely to lead to positive outcomes. ${ }^{17}$ A previous audit of a healthy lifestyle initiative in NZ found there was a need to assess stage of change of families prior to programme commencement, as it was not uncommon for the coordinator to visit an empty house, impacting on the use of valuable resource.$^{18} \mathrm{~A}$ new model was created, which incorporated assessment of readiness to make healthy lifestyle change. ${ }^{17}$ The service, created and named 'Whānau Pakari', is a multi-disciplinary assessment and intervention programme for children/ adolescents with obesity, with a randomised clinical trial (RCT) embedded within the service to assess outcomes. ${ }^{17}$ The results of the RCT showed a mean change in BMI SD score (SDS) at 12 months from baseline of -0.12 in the low-intensity control group (6-month assessments and advice), and -0.10 in the high-intensity intervention group (weekly group sessions with 6-month assessments and advice).${ }^{19}$ However, if $\geq 70 \%$ attendance was achieved in the high-intensity intervention, the effect was doubled (-0.22 SDS). ${ }^{19}$ Baseline stage of change in the caregiver (committed family member or legal guardian) in both groups was not different-control group: preparation/ action $(\mathrm{n}=54,56 \%)$ versus pre-contemplation/contemplation ( $\mathrm{n}=43,44 \%)$; intervention group: preparation/ action $(\mathrm{n}=43 ; 43 \%)$ versus pre-contemplation/contemplation $(\mathrm{n}=57,57 \%$; $\mathrm{p}=0.08)$.

The aims of this study were twofold: first, to investigate whether the caregiver's stage of change at baseline using a standardised measure of readiness for change ${ }^{3}$ (adapted to focus on attitudes towards eating habits, weight and physical activity) predicted our primary outcome of the trial (BMI SDS) and/or the secondary outcomes in the Whānau Pakari 12 month intervention (such as waist circumference, number of breakfasts eaten, servings of fruit and vegetables, sweet drink consumption, 550-m walk/run time, steps per day, indices on quality of life and behaviour checklists and biochemical markers); and second, to determine whether stage of change was predictive of adherence to treatment. It was hypothesised that those caregivers expressing a higher stage of change 
(ie, preparation and action) would see greater improvements in their children/adolescents in terms of primary and secondary outcomes and demonstrate greater programme adherence.

\section{METHODS \\ Participants}

Taranaki has a population of approximately 23139 children aged $0-15$ years, of which $81 \%$ identify as NZ European (NZE), 28\% as Māori and 1\% as other ethnicity (multiple ethnicities possible).$^{20}$ Eligible participants (recruited January 2012 to August 2014 as part of the Whānau Pakari trial) were aged $5-16$ years and had a BMI $\geq 98$ th centile or BMI $>91$ st centile with weight-related comorbidities. ${ }^{21}$ BMI percentile and BMI SDS were calculated as per UK 1990 growth reference data, using the KIGS auxology software (Pfizer Endocrine Care).$^{22}$ One aspect of eligibility was being pre-contemplative or above on the readiness for change scoring. We purposely set the bar low for readiness to change (ie, below the pre-contemplative level) to assess whether degree of readiness for change predicts outcome ${ }^{17}$; therefore, only those classed as not ready for change on stage of change assessment were excluded from this study.

The rationale and study design for the Whānau Pakari trial have been previously reported, as have 12 month outcomes. ${ }^{17} 19$ In brief, the RCT compared a 12 month intensive intervention with home-based comprehensive assessments (medical, dietary, physical activity and psychology screening) and weekly activity sessions (group sessions for 12 months, including physical activity, nutrition and psychology content) with a minimal intensity control with home-based assessments only, including 6-month follow-up, conducted in Taranaki, NZ. For the purposes of this study, given we were interested in stage of change in relation to outcome, only participants in the intensive intervention arm were included.

\section{Assessments}

Whānau Pakari was a novel home-based 'demedicalised' model (no hospital visits, with a comprehensive weight-related medical assessment in the home) that was family-centred. The assessment included dietary, physical and psychological review, with evaluation of stage of change. Secondary outcomes included waist circumference; number of breakfasts eaten per week; servings of fruit and vegetables per day; consumption of sweet drinks per day $(\mathrm{mL}) ; 550-\mathrm{m}$ walk/run time $(\mathrm{min})^{23}$; actual steps per day and actual time spent on moderate-intensity to very vigorous physical activity per day - measured using accelerometers (ActiGraph wGT3X-BT; Actigraph LLC, Pensacola, Florida, USA); total reported activity per day (min); reported screen time per day (min); total generic scaled score (child); total generic scaled score (parent) — both from Pediatric Quality of Life questionnaire ${ }^{24}$; Achenbach Child Behaviour Checklist internalising, externalising and total raw scores ${ }^{25}$; as well as glycated haemoglobin (HbAlc) and fasting insulin (pmol/L).

At the end of the baseline assessment, two assessments of readiness for change were undertaken. The healthy lifestyle co-ordinator's qualitative judgement of stage of change, ranked pre-contemplation, contemplation and preparation/action for child (if $>11$ years of age) and committed family member/caregiver was recorded first. The trial-designed questionnaire was completed by the child (if $>11$ years of age) and another version of the questionnaire for the caregiver (in every participant). For comparative analysis, preparation was merged with action, resulting in three possible stages of change. This was a pragmatic decision based on clinical grounds; if stage of change was found to be a predictor of outcome, a caregiver that demonstrated preparation or action ratings for stage of change would be likely to be offered a place for their family in the intensive intervention in the 'real-world', fiscally constrained setting outside of an RCT; whereas those that were pre-contemplative or contemplative were more likely to be offered motivational interviewing, and a follow-up assessment at a later date.

\section{Readiness for change as a dichotomous measure}

The readiness for change questionnaire was based on Rollnick $e t a l$ s original readiness to change questionnaire, ${ }^{3}$ which we modified to focus on beliefs around weight, eating habits and physical activity levels. A 5-point Likert scale was used. Given the complexity of obesity, additional questions were added to the original questionnaire, resulting in a 21-item child/adolescent questionnaire and a 27-item questionnaire for the family member, with six extra questions related to attitudes/behaviour of the wider family unit. The questionnaire was tested for understanding and comprehension in a randomly selected cohort of clinic patients prior to trial commencement, who were underweight, normal weight and overweight. This pilot testing found the questionnaire was acceptable for use (ie, underweight children were scored pre-contemplative).

Questions were reverse keyed in their language to negate the need to reverse the pre-contemplative scaled score when comparing the three scores for each stage of change with each other. Scoring was undertaken, which calculated the sum totals for each stage of change (pre-contemplation, contemplation or preparation/action). This was divided by the number of questions asked to obtain an adjusted score for each stage of change. The highest adjusted score was designated as the stage of change of the child/adolescent or family member.

\section{Attendance}

Attendance was calculated as a percentage based on the number of weekly activity sessions offered to each individual family over the 12-month period of their involvement in the programme. 


\section{Participant and public involvement}

This study was designed in response to our discussions working with families and the need for a more sophisticated form of triage for referred participants wishing to engage with the healthy lifestyle programme. Participants were not officially involved in study design. Results of this secondary analysis will not be officially disseminated to study participants; however, we ensure that findings are published in open access formats wherever possible so they are freely available to the community.

\section{Power calculation}

A total of 68 study participants had attendance data and completed the 12-month assessments. Based on the changes from baseline observed at 12 months in our study population, and with $\mathrm{n}$ of 32 and 36 in each group, our study was powered to detect statistically significant differences in change from baseline in BMI of \pm 0.21 SDS, in waist circumference of $\pm 3.5 \mathrm{~cm}$ and in parent's total generic scaled score of \pm 11.1 , with $\alpha=0.05 \%$ and $80 \%$ power.

\section{Data analyses}

Cronbach's alpha (a numerical measure of internal consistency) was used to establish the reliability of the quantitative readiness for change questionnaire. The agreement between qualitative and quantitative assessments was examined using Spearman's rank $(\rho)$ and Kendall's $(\tau)$ correlation coefficients. Generalised linear regression models were used to compare study outcomes (as described above and in the quantitative stage of change and outcome measures section of the results) in the children according to the family member's stage of change (pre-contemplation/contemplation vs preparation/action). Models were adjusted for child/adolescent's ethnicity, gender, age at assessment, level of stage of change, economic deprivation, as well as the respective parameter at baseline.

Subgroup analyses were also performed examining the associations within age groups; specifically, among children aged less than 11 years of age and among those aged 11 years or older. Demographic parameters were compared using $\chi^{2}$ tests and non-parametric Kruskal-Wallis tests. Multivariable models were run as described previously, except that age at assessment was no longer included as a covariate.

Statistical analyses were performed in SAS V.9.4 (SAS Institute, Cary, NC, USA) and Minitab V.16 (Pennsylvania State University, State College, PA, USA). All statistical tests were two-tailed, with significance level maintained at $\mathrm{p}<0.05$.

\section{RESULTS}

A total of 102 participants were randomised to the intense intervention arm. The flow of participants through the trial has been previously reported. ${ }^{19}$ Two participants were excluded after randomisation; due to new medical diagnoses likely to affect weight status. Of the remaining 100 , one participant relocated, never attending a session and three had longer attendance than offered in the intervention, leaving 96 participants with complete
Table 1 Baseline characteristics of the 96 intervention participants with complete attendance data. Age and BMI data are means and SD

\begin{tabular}{|c|c|}
\hline & Intervention \\
\hline$n$ & 96 \\
\hline Age (years) & $10.7(3.07)$ \\
\hline Females (n, \%) & $48(50.0 \%)$ \\
\hline \multicolumn{2}{|l|}{ Ethnicity $(\mathrm{n}, \%)^{\star}$} \\
\hline Māori & $45(46.9 \%)$ \\
\hline New Zealand European & $40(41.7 \%)$ \\
\hline Asian & $5(5.2 \%)$ \\
\hline Pacific & $2(2.1 \%)$ \\
\hline Other & $4(4.1 \%)$ \\
\hline \multicolumn{2}{|l|}{ Anthropometry } \\
\hline BMI $\left(\mathrm{kg} / \mathrm{m}^{2}\right)$ & $29.6(6.11)$ \\
\hline BMI SDS & $3.11(0.59)$ \\
\hline \multicolumn{2}{|l|}{ Deprivation index (quintile)† } \\
\hline 1 (least deprived) & $14(14.6 \%)$ \\
\hline 2 & $19(19.8 \%)$ \\
\hline 3 & 17 (17.7\%) \\
\hline 4 & $22(22.9 \%)$ \\
\hline 5 (most deprived) & $24(25 \%)$ \\
\hline \multicolumn{2}{|l|}{ Accompanying adult } \\
\hline Mother & $74(77.1 \%)$ \\
\hline BMI $\left(\mathrm{kg} / \mathrm{m}^{2}\right) \ddagger$ & $32.6(7.26)$ \\
\hline $\mathrm{BMI} \geq 30 \mathrm{~kg} / \mathrm{m}^{2} \ddagger$ & $56(61.5 \%)$ \\
\hline \multicolumn{2}{|l|}{ Living arrangements§ } \\
\hline Two-parent household & $52(55.9 \%)$ \\
\hline One-parent household & $37(39.8 \%)$ \\
\hline Other & $4(4.3 \%)$ \\
\hline
\end{tabular}

*Prioritised ethnic group.

†Quintiles of level of household deprivation. ${ }^{31}$

$\ddagger$ Parameter was measured where consented to $(n=91)$,

otherwise not included. BMI $\geq 30 \mathrm{~kg} / \mathrm{m}^{2}$ adult cut-off for obese. $\S n=93$.

BMI, body mass index; SDS, SD score.

attendance data. Table 1 shows the baseline characteristics of the participants.

\section{Reliability}

Reliability of the readiness for change questionnaire (caregiver and child/adolescent) using Cronbach's alpha was 0.62 for the child/adolescent questionnaire and 0.65 for caregiver questionnaire.

Statistically, there was no evidence of an agreement found between the caregiver's and child/adolescent's questionnaires as per Kendall's correlation coefficient $(\tau=0.60 ; \mathrm{p}=0.11)$. However, scores from the caregiver's questionnaire and qualitative assessment were positively correlated $(\rho=0.28 ; p=0.005)$ and showed moderate agreement $(\tau=0.64 ; p=0.03)$. Similarly, the child/adolescent's questionnaire and qualitative assessment scores 
Table 2 Change at 12 months from baseline in association with the quantitative stage of change of caregiver at baseline (preparation/action vs pre-contemplation/contemplation)

\begin{tabular}{|c|c|c|c|c|}
\hline & Preparation/action & $\begin{array}{l}\text { Pre-contemplation/ } \\
\text { contemplation* }\end{array}$ & Difference & $\mathrm{P}$ valuet \\
\hline N & 32 & 36 & & \\
\hline \multicolumn{5}{|l|}{ Primary outcome } \\
\hline BMI SDS & $-0.16(-0.27,-0.05)$ & $-0.08(-0.18,0.03)$ & $-0.09(-0.24,0.07)$ & 0.27 \\
\hline \multicolumn{5}{|l|}{ Secondary outcomes } \\
\hline Waist circumference $(\mathrm{cm})$ & $1.5(-0.5,3.5)$ & $2.7(0.9,4.6)$ & $-1.3(-4.0,1.5)$ & 0.36 \\
\hline Number of breakfasts eaten & $0.2(-0.5,0.8)$ & $0.1(-0.4,0.7)$ & $0.0(-0.8,0.9)$ & 0.95 \\
\hline Servings fruit/vegetables per day (n) & $0.7(0.0,1.3)$ & $1.2(0.6,1.8)$ & $-0.5(-1.4,0.4)$ & 0.24 \\
\hline Sweet drinks per day $(\mathrm{mL})$ & $-191(-261,-121)$ & $-126(-191,-62)$ & $-65(-164,35)$ & 0.20 \\
\hline 550-m walk/run time (min) & $-0.5(-0.7,-0.3)$ & $-0.5(-0.6,-0.3)$ & $0.0(-0.3,0.3)$ & 0.84 \\
\hline Actual steps per day (n) & $203(-890,1296)$ & $-403(-1319,513)$ & $605(-889,2100)$ & 0.41 \\
\hline $\begin{array}{l}\text { Actual moderate-intensity to very vigorous physical } \\
\text { activity per day (min) }\end{array}$ & $7(-3,18)$ & $-9(-18,-0)$ & $16(2,30)$ & 0.03 \\
\hline Total reported activity per day (min) & $25(-6,55)$ & $20(8,48)$ & $5(-38,48)$ & 0.82 \\
\hline Reported screen time per day (min) & $-17(-51,18)$ & $-21(-53,11)$ & $4(-45,53)$ & 0.86 \\
\hline Total generic scaled score-child $\neq$ & $7.9(3.2,12.7)$ & $7.4(3.0,11.8)$ & $0.5(-6.3,7.3)$ & 0.87 \\
\hline Total generic scaled score-parentł & $9.2(2.8,15.6)$ & $7.7(1.8,13.5)$ & $1.5(-7.7,10.8)$ & 0.74 \\
\hline $\mathrm{CBCL}$ internalising raw score & $-3.2(-5.5,-0.8)$ & $-3.4(-5.6,-1.2)$ & $0.2(-3.1,3.6)$ & 0.89 \\
\hline $\mathrm{CBCL}$ externalising raw score & $-3.1(-5.6,-0.6)$ & $-2.0(-4.3,0.3)$ & $-1.1(-4.6,2.4)$ & 0.52 \\
\hline CBCL total raw score & $-11.7(-18.5,-4.8)$ & $-8.5(-14.9,-4.8)$ & $-3.1(-12.9,6.6)$ & 0.52 \\
\hline $\mathrm{HbA} 1 \mathrm{c}(\mathrm{mmol} / \mathrm{mol}) \S$ & $-0.8(-2.3,0.7)$ & $-0.3(-1.7,1.1)$ & $-0.5(-2.6,1.6)$ & 0.63 \\
\hline Fasting insulin (pmol/L)ף & $-10(-42,24)$ & $7(-24,39)$ & $-17(-65,31)$ & 0.48 \\
\hline
\end{tabular}

${ }^{*}$ Data are means and $95 \%$ Cls adjusted for child/adolescent's ethnicity, gender, level of deprivation, age at assessment and the respective parameter at baseline.

†P value for a difference in change from baseline between pre-contemplation/contemplation and action groups.

$\ddagger$ Total overall health-related quality of life score out of 100 for the PedsQL questionnaire.

$\S n=51$.

१n $=56$.

BMI SDS, body mass index SD score; CBCL, Achenbach Child Behaviour Checklist; HbA1c, glycated haemoglobin; PedsQL,

Pediatric quality of life.

were also correlated $(\rho=0.38 ; p=0.01)$, with some evidence of moderate agreement $(\tau=0.69 ; \mathrm{p}=0.05)$.

\section{Quantitative stage of change and outcome measures}

Of the 96 participants, 68 had attendance data and assessment data at 12 months.

Table 2 shows the stratified association between quantitative stage of change (caregiver) at baseline assessment and outcome at 12 months.

There were no differences in BMI SDS change from baseline between groups according to caregiver's stage of change ( $\mathrm{p}=0.27$; table 2 ). Among secondary outcomes, family members in the stage of preparation/action spent 16 min more on moderate-intensity to very vigorous physical activity per day compared with those in pre-contemplation/contemplation $(\mathrm{p}=0.03$; table 2$)$. There were no other differences in secondary outcomes (table 2).

The caregiver's stage of change was not associated with the child/adolescent's ethnicity $(\mathrm{p}=0.54)$, gender $(\mathrm{p}=0.71)$, level of household deprivation $(\mathrm{p}=0.88)$, or age at assessment $(\mathrm{p}=0.10)$. This was also seen for the qualitative stage of change in the caregiver $(\mathrm{p}=0.63 ; \mathrm{p}=0.55$; $\mathrm{p}=0.08$ and $\mathrm{p}=0.59$, respectively).

\section{Age of child}

There was no association between changes at 12 months from baseline among children based on age and caregiver's readiness for change (online supplementary tables 1 and 2), apart from a between-group difference in the $<11$-year group for actual moderate to very vigorous activity $(\mathrm{p}=0.02)$.

\section{Attendance}

Median attendance at the weekly activity sessions was $35 \%$ (IQR 66\%). The quantitative readiness for change questionnaire for the caregiver was used for all analyses of outcome, as these were available for the entire cohort. In multivariate analyses, there was no association between quantitative stage of change of the caregiver and attendance overall in the intervention; preparation/action 
$38.3 \% \quad(\mathrm{n}=43)$ versus pre-contemplation/contemplation $41.0 \%(\mathrm{n}=53 ; \mathrm{p}=0.54)$.

For the qualitative assessment of readiness for change of the caregiver, overall attendance was greater for the pre-contemplation/contemplation group than in the preparation/action group $(49.6 \%$ vs $36.5 \%$; $\mathrm{p}=0.009)$. In addition, the greater the level of household deprivation, the lower the attendance at the intervention overall $(p=0.004)$, while mean attendance was greater among NZE compared with non-NZE ( $49.5 \%$ vs $36.6 \%$; $p=0.003$ ). Further analyses were based on the quantitative measure of readiness for change.

\section{DISCUSSION}

This study found that assessment of accompanying caregiver's stage of change on quantitative assessment at baseline was not a predictor of primary or secondary outcomes, or overall adherence in a multi-disciplinary assessment and intervention programme for children and adolescents with obesity. This is important, given that attendance was found in the intensive intervention to have a doubling of effect in terms of BMI SDS reduction. ${ }^{19}$ Deprivation and ethnicity did not affect caregiver stage of change.

It was not surprising that caregiver's stage of readiness to make lifestyle changes was not a good predictor of child/ adolescent outcome. Indeed, caregiver readiness is one factor in a complex multitude of factors predicting success in achieving reductions in weight status, such as perception of child weight status, and recognition of weight as a problem. ${ }^{112}$ Environmental factors, such as access to transport to sessions, food security and availability of a caregiver to attend sessions also will affect outcome. Such factors are likely to be why the results from this study were not significant. While readiness models have shown promise in child obesity pilot programmes ${ }^{26}$ it is clear that acknowledgement of child obesity as a problem by the individual and family members is essential for lifestyle change to occur. ${ }^{5}$ Our findings are consistent with a previous Icelandic study, which found that parental confidence for doing well in treatment (18week intervention) was not associated with child outcome at 1-year follow-up. ${ }^{10}$ The stage of change model is a snapshot in time, and does not necessarily represent future behaviour. ${ }^{12}$

The actions of parents and their stage of change are inherently linked to outcomes for a child; a study of 142 families found that changes in parental BMI SDS significantly predicted child's BMI SDS change at 0-6 and 0-24 months in a family-based intervention. ${ }^{27}$ However, the situation is complex; a recent study showed that children whose parents perceive them to be overweight are more likely to have negative views about their own body size, and are more likely to be trying to lose weight. In these children, a counterintuitive association between parents' perceptions of their children as being overweight, and subsequent weight gain in those children was found. ${ }^{28}$ It was previously observed that several demographic factors and personal perceptions are associated with a parent's readiness to assist with their child's weight status. ${ }^{5}$ These findings highlight that in any multi-disciplinary intervention programme, healthy lifestyle change needs to be the focus, rather than concepts of weight or obesity.

While the transtheoretical model based on readiness for change offers a comprehensive framework, assessment instruments, such as the University of Rhode Island Change Assessment Scale, the S-Weight/P-Weight and the Decisional Balance Inventory offer practical applications. ${ }^{29}$ Review of these measures found the S-Weight/P-Weight to be the most efficient, providing stage of change and the process of change an individual is using. ${ }^{29}$ The S-Weight consists of five items assessing stage of change, with the P-Weight having 34 items measuring four processes of change; emotional re-evaluation, weight management actions, environmental restructuring and weight consequences evaluation. ${ }^{29}$ These were created by international expert consensus. ${ }^{30}$ However, to our knowledge, such instruments are not available for use in both parents and children.

Strengths of this study include the use of both qualitative and quantitative assessments of readiness for change. Due to the high representation from indigenous populations and those from the most deprived households, analysis in terms of ethnicity and deprivation were possible. Limitations of this study include lack of measurement of self-efficacy and overall confidence to make changes. Confidence in making changes in physical activity and eating behaviour were included in both quantitative questionnaires, however. The assessment tool has not been used previously, and sample size was also relatively small, and potentially underpowered to detect statistically significant differences for certain outcomes. This programme required the attendance of an accompanying adult, irrespective of the age of the child/adolescent, yet the age of the child did not appear to have an effect on outcome. It could be argued that preparation and action should not be merged for the purposes of analysis. However, as outlined previously, this was a decision based on how the outcomes would be used in clinical practice.

It had been hoped that, if the readiness for change measure was predictive of success in outcome measures, then creation of paired interventions relating to motivation for change for those in earlier stages of change, superseded by direct interventions for those in later stages could achieve less attrition from the programme. ${ }^{17}$ This would lead to efficiency gains and cost-effective utilisation of finite health resource. However, this was not the case. Further development of a measure of readiness for change in this context is warranted.

In conclusion, determination of caregiver's readiness for change in this multi-disciplinary assessment and intervention for children/adolescents with obesity was not a successful predictor of outcome or attendance. While expert panels are recommending determination of a family's readiness for change in the overall psychosocial assessment of a child with obesity, ${ }^{9}$ this process remains ill defined. Future research needs to determine participants' factors for success in making healthy lifestyle changes. 
Author affiliations

${ }^{1}$ Department of Paediatrics, Taranaki District Health Board, New Plymouth, New Zealand

${ }^{2}$ Liggins Institute, The University of Auckland, Auckland, New Zealand

${ }^{3}$ Taranaki District Health Board, New Plymouth, New Zealand

${ }^{4}$ Faculty of Medical and Health Sciences, The University of Auckland, Auckland, New

Zealand

${ }^{5}$ Department of Paediatrics, The University of Auckland, Auckland, New Zealand

Contributors YCA designed the study, co-ordinated the trial, provided paediatrician oversight, drafted the initial manuscript and approved the final manuscript as submitted. GMSD created the trial-designed readiness for change quantitative assessment tool. LEW recruited participants and undertook assessments and data entry. KFT provided psychologist oversight and analysis of patient data. TW assisted with study design and reliability/validity of the questionnaires. CG is secondary supervisor for the research team and assisted with study design. TLC supervised data entry and cleaning. AS assisted with data entry and attendance data. JGBD undertook data analysis. WC contributed to study design. PH contributed to study design and supervised the research team. All authors contributed to discussions and critically appraised the manuscript. All authors approved the final manuscript as submitted and agree to be accountable for all aspects of the work.

Funding This work was supported by grants from the Health Research Council of NZ, Royal Australasian College of Physicians, Maurice and Phyllis Paykel Trust, Taranaki Medical Foundation, and Lotteries Health Research.

Competing interests YCA reports grants from Health Research Council of NZ, grants from Royal Australasian College of Physicians, grants from Maurice and Phyllis Paykel Trust, grants from Taranaki Medical Foundation during the conduct of the study; TLC and AS report grants from Taranaki Medical Foundation, grants from Maurice and Phyllis Paykel Trust, grants from Lotteries Health Research during the conduct of the study; $\mathrm{PH}$ reports grants from Lotteries Health Research during the conduct of the study.

\section{Patient consent for publication Not required}

Ethics approval Ethics approval for the trial was granted by the Central Health and Disability Ethics Committee (NZ) (CEN/11/09/054).

Provenance and peer review Not commissioned; externally peer reviewed.

Data sharing statement Anonymised and de-identified data will be made available to other investigators upon request. Interested readers should contact the senior author PH (p.hofman@auckland.ac.nz) to obtain the data.

Open access This is an open access article distributed in accordance with the Creative Commons Attribution Non Commercial (CC BY-NC 4.0) license, which permits others to distribute, remix, adapt, build upon this work non-commercially, and license their derivative works on different terms, provided the original work is properly cited, appropriate credit is given, any changes made indicated, and the use is non-commercial. See: http://creativecommons.org/licenses/by-nc/4.0/.

\section{REFERENCES}

1. Prochaska JO, DiClemente CC. Transtheoretical therapy: Toward a more integrative model of change. Psychotherapy: Theory, Research \& Practice 1982;19:276-88.

2. DiClemente CC, Prochaska JO. Self-change and therapy change of smoking behavior: a comparison of processes of change in cessation and maintenance. Addict Behav 1982;7:133-42.

3. Rollnick S, Heather N, Gold R, et al. Development of a short 'readiness to change' questionnaire for use in brief, opportunistic interventions among excessive drinkers. Br J Addict 1992;87:743-54.

4. Hoke MM, Timmerman GM. Transtheoretical Model: Potential Usefulness With Overweight Rural Mexican American Women. Hispanic Health Care International 2011;9:41-9.

5. Rhee KE, De Lago CW, Arscott-Mills T, et al. Factors associated with parental readiness to make changes for overweight children. Pediatrics 2005;116:e94-e101.

6. da Silva DF, Bianchini JA, Lopera CA, et al. Impact of readiness to change behavior on the effects of a multidisciplinary intervention in obese Brazilian children and adolescents. Appetite 2015;87:229-35.
7. Lau DCW, Douketis JD, Morrison KM, et al. 2006 Canadian clinical practice guidelines on the management and prevention of obesity in adults and children [summary]. CMAJ 2007;176:S1-S13.

8. Krebs NF, Himes JH, Jacobson D, et al. Assessment of child and adolescent overweight and obesity. Pediatrics 2007;120 Suppl 4:S193-S228.

9. Daniels SR, Jacobson MS, McCrindle BW, et al. American Heart Association Childhood Obesity Research Summit: executive summary. Circulation 2009;119:2114-23.

10. Gunnarsdottir T, Njardvik U, Olafsdottir AS, et al. The role of parental motivation in family-based treatment for childhood obesity. Obesity 2011;19:1654-62.

11. Jones AR, Parkinson KN, Drewett RF, et al. Parental perceptions of weight status in children: the Gateshead Millennium Study. Int J Obes 2011;35:953-62.

12. Park $\mathrm{MH}$, Falconer $\mathrm{CL}$, Croker $\mathrm{H}$, et al. Predictors of health-related behaviour change in parents of overweight children in England. Prev Med 2014;62:20-4.

13. Giannisi F, Pervanidou P, Michalaki E, et al. Parental readiness to implement life-style behaviour changes in relation to children's excess weight. J Paediatr Child Health 2014;50:476-81.

14. Kelleher E, Davoren MP, Harrington JM, et al. Barriers and facilitators to initial and continued attendance at community-based lifestyle programmes among families of overweight and obese children: a systematic review. Obes Rev 2017;18:183-94.

15. Teevale T, Taufa S, Percival T. Acceptability and non-compliance in a family-led weight-management programme for obese Pacific children. Public Health Nutr 2015;18:2625-33.

16. Rhee KE, McEachern R, Jelalian E. Parent readiness to change differs for overweight child dietary and physical activity behaviors. $J$ Acad Nutr Diet 2014:114:1601-10.

17. Anderson YC, Wynter LE, Moller KR, et al. The effect of a multidisciplinary obesity intervention compared to usual practice in those ready to make lifestyle changes: design and rationale of Whanau Pakari. BMC Obes 2015;2:41.

18. Anderson YC, Taylor GM, Grant CC, et al. The Green Prescription Active Families programme in Taranaki, New Zealand 2007-2009: Did it reach children in need? J Prim Health Care 2015;7:192-7.

19. Anderson YC, Wynter LE, Grant CC, et al. A Novel Home-Based Intervention for Child and Adolescent Obesity: The Results of the Whānau Pakari Randomized Controlled Trial. Obesity 2017;25:1965-73.

20. Census. Ethnic group by age group and sex. $2013 \mathrm{http} / / /$ nzdotstat. stats.govt.nz/wbos/Index.aspx?DataSetCode=TABLECODE8021\# (Accessed 18 Nov 2014).

21. Cole TJ. A chart to link child centiles of body mass index, weight and height. Eur J Clin Nutr 2002;56:1194-9.

22. Freeman JV, Cole TJ, Chinn S, et al. Cross sectional stature and weight reference curves for the UK, 1990. Arch Dis Child 1995;73:17-24

23. Hamlin MJ, Fraser M, Lizamore CA, et al. Measurement of cardiorespiratory fitness in children from two commonly used field tests after accounting for body fatness and maturity. J Hum Kinet 2014;40:83-92

24. Varni JW, Burwinkle TM, Seid M, et al. The PedsQL 4.0 as a pediatric population health measure: feasibility, reliability, and validity. Ambul Pediatr 2003;3:329-41.

25. Achenbach TM, Ruffle TM. The Child Behavior Checklist and related forms for assessing behavioral/emotional problems and competencies. Pediatr Rev 2000;21:265-71.

26. Kwapiszewski RM, Lee Wallace A. A Pilot Program to Identify and Reverse Childhood Obesity in a Primary Care Clinic. Clin Pediatr 2011;50:630-5

27. Wrotniak BH, Epstein LH, Paluch RA, et al. Parent weight change as a predictor of child weight change in family-based behavioral obesity treatment. Arch Pediatr Adolesc Med 2004;158:342-7.

28. Robinson E, Sutin AR. Parents' Perceptions of Their Children as Overweight and Children's Weight Concerns and Weight Gain. Psychol Sci 2017;28:320-9.

29. Ceccarini M, Borrello M, Pietrabissa G, et al. Assessing motivation and readiness to change for weight management and control: an in-depth evaluation of three sets of instruments. Front Psychol 2015;6:511

30. Andrés A, Saldaña C, Gómez-Benito J. Establishing the stages and processes of change for weight loss by consensus of experts. Obesity 2009;17:1717-23.

31. New Zealand Deprivation Index. 2006. https://koordinates.com/layer/ 1066-nz-deprivation-index-2006/ (Accessed 2 Dec 2017) 